\title{
Laws of Ecology and Their Promise of Explanations
}

\author{
Viorel Pâslaru*
}

\begin{abstract}
A number of ecologists have put forward various proposals that ecology has laws, yet they have not explicated what role laws play in ecological explanations. Marcel Weber (1999), Lev Ginzburg and Mark Colyvan (2004) correct this deficiency and also make their case for laws of ecology: the principle of competitive exclusion and Malthus's law of exponential growth respectively. According to Weber, the principle of competitive exclusion explains phenomena (1) by direct application, or (2) by describing a default state from which observed phenomena deviate and mechanisms are called to account for the discrepancy. Independently of Weber, Ginzburg and Colyvan articulate a role similar to (2) for Malthus's law. I argue that Weber's proposition of explanation by direct application is not consistent with Gause's account of "bottle experiments" that he uses to support it and does not do justice to ecologists' explanatory practice. To address these problems, I articulate an alternative account of explanation by direct application-the covering-law model — based on a proposal by Elgin and Sober (2002) and show that even in this proposal mechanisms play a key explanatory role. I also demonstrate how the covering-law model accounts for how Malthus's law can explain by direct application and for its role of descriptor of a default state. Finally, I argue that the views on laws as components in covering-law model explanations or as descriptors of default states do not give sufficient attention to the prominent explanatory role of mechanisms and to the demanding task of identifying and describing them, and ought to be corrected.
\end{abstract}

\section{Keywords}

ecology $\bullet$ explanation $\bullet$ laws $\bullet$ mechanisms $\bullet$ models

\section{Introduction}

In contrast to the students of physics, students of ecology are not taught that their science offers an unequivocal set of laws that should be used to explain and predict ecological phenomena. However, a number of ecologists and a few philosophers of science have argued that ecology has laws (Colyvan and Ginzburg 2003b, Ginzburg and Colyvan 2004; Weber 1999; Turchin 2001; Berryman 2003; Mikkelson 2003; Lange 2005; West and Brown 2004; Cooper 2003;

\footnotetext{
*Department of Philosophy, University of Dayton, 300 College Park, Dayton, OH 45469-1546, USA, vpaslaru1@udayton.edu
} 
Linquist et al. 2016), and some have even argued that it is analogous to physics (Colyvan and Ginzburg 2010). Even if successful, the case for laws of ecology requires an explication of their role in explanations and a clarification of their explanatory weight relative to that of mechanisms, which are often invoked alongside laws, yet these issues have not been examined sufficiently. This article contributes to remedying this deficiency.

Some friends of laws of ecology maintain that we should not understand the laws of ecology as like the laws of physics. Rather, they should be understood based on the explanatory and predictive practice of ecology, which shows that lawfulness is a matter of degree and of invariance over a range of possibilities (Cooper 2003, 113-114). Lange (2005) argues that ecological laws are autonomous from microphysical states, which prevents ecological explanations from being reduced to explanations of physics. Others insist that to recognize laws of ecology, we need to clear up some misconceptions about the laws of physics: they are not exceptionless, do not make precise predictions, and cannot be mere regularities. Freed from these misconceptions, we can see that ecology is analogous to physics and has laws similar to it (Colyvan and Ginzburg 2010). These arguments and ecologists' contributions have led to several inventories of laws of ecology, yet there is no consensus list of laws, but rather multiple and partially overlapping proposals, as follows.

Ginzburg (1986) argued that Malthusian exponential growth is a law of ecology and for using it as a basis for articulating the theory of population biology (Colyvan and Ginzburg 2003a, 2003b). In addition to Malthus's law, Berryman $(1999,2003)$ showed that ecology uses laws that cover intraspecific cooperation, competition, predator-prey interaction, and limiting factors acting on a population, such as Liebig's law of the minimum. He is one of the few that claims that these laws are not specific to ecology, but are reformulations of principles from general systems theory, physics and chemistry. Turchin's (2001) list of laws overlaps with Berryman's, but adds the law of self-limiting growth of populations and consumer-resource oscillations. Examining G. E. Hutchinson's $(1957,1961)$ considerations of the conditions of coexistence of competing species in their ecological niches, Weber (1999) made the case for the principle of competitive exclusion as a law of ecology, a view adopted later by Raerinne and Baedke (2015). Furthermore, Lange $(2000,2005)$ identified three examples of ecological laws: Liebig's law of the minimum, the law of constant final yield, the 3/2 thinning law, and the area law from island biogeography. And Mikkelson (2003) argued that ecology is primarily a law-oriented science, and that some generalizations that refer to structural and/or functional kinds in ecology are its genuine laws.

Besides Malthus's law, Ginzburg and Colyvan (2004) argued that ecological allometries, which are "statistical regularities that hold between various biological and ecological quantities" (12), are also good candidates for laws of ecology. For example, Kleiber allometry shows that basal metabolic rate is proportional to a $\frac{3}{4}$ power of body weight. Other allometries are those discovered by Fenchel, Damuth, and Calder (Ginzburg and Colyvan 2004, 16-21). 1

The goal of ecologists to show that ecology has genuine laws is typically tied to their concern to demonstrate that it is a science on a par with physics and not just a historical investigation. This endeavor is incomplete because it does not show how the identified laws, or regularities, perform their work in explanations and predictions. Philosophers of ecology have gone a step further in this regard and showed that laws of ecology-understood in a restricted sense as explicated above-play two explanatory roles, as outlined by Weber $(1999,81)$ : (1) they can be part of covering-law style explanations, or (2) they describe a default state and that description

\footnotetext{
${ }^{1}$ Not everybody agrees with these views on laws in ecology and its similarity to physics. For disagreements see for example O'Hara (2005) and Lockwood (2008). The latter disputes that Malthus's growth is a law of ecology and argues that the arguments for lawhood from analogy to physics are based on a misunderstanding of physics.
} 
is used to formulate contrastive explanations that also appeal to mechanisms to account for departure of the observed state from the default state. Ginzburg and Colyvan have extensively argued in favor of this second role. Whether all aforementioned laws of ecology play both roles, or only one of them, and in what cases, or none is an extensive research project in itself that is important to pursue to give a more extensive account of their explanatory role in ecology.

In this article, my objective is to demonstrate the following: (i) Weber's claim that the competitive exclusion principle explains by direct application is not supported by Gause's work that he cites to buttress his proposal-Gause insisted on describing the mechanisms responsible for competitive exclusion - nor by other aspects of explanatory practice of ecologists. (ii) The covering-law model explanation offers a better alternative view on explanation by direct application. On this view, competitive exclusion principle as well as other laws can explain by being a part of covering-law models, which also require descriptions of mechanisms. I use an example from Tilman's research on resource competition to illustrate the covering-law model explanation. Although Ginzburg and Colyvan did not foresee the role of Malthus's law in covering-law style explanations, the covering-law model can accommodate it. Finally, (iii) even when laws describe a default state, as Ginzburg and Colyvan argue, or are assumed as a contrast class in Weber's view, it is mechanisms that do the heavy explanatory work. In light of (i), (ii) and (iii), I conclude that the case for laws in ecological explanations also makes the case for the centrality of mechanisms in ecological explanations, and further work should be directed toward their analysis and classification.

\section{Laws of Ecology in Covering-Law Style Explanations}

\subsection{An Interpretation of Explanation by Direct Application of Laws and Resulting Issues}

Weber (1999) contends the principle of competitive exclusion explains by direct application to a situation where competitive exclusion obtains regularly, and the case of the "bottle experiment" of G. F. Gause "contains all the elements of this basic type of competition-based ecological explanation" (81). Gause's experiment on paramecia showed that (1) P. aurelia always drove $P$. caudatum to extinction, while (2) P. caudatum and P. bursaria coexisted. The principle easily explains regularity (1), which is an instance of it, but not regularity (2), which is not an instance. Weber's description of the explanatory role of the principle applied to the first regularity is limited to the following: "The explanation given is simply a direct application of the principle itself. The most straightforward analysis for such cases, I suggest, is to say that the principle functions as a law-like generalization which tells us that, under the given conditions, one of the two-species communities had to be unstable (by causal necessity)" (81). I interpret this brief description as a proposal to understand the role of the principle of competitive exclusion in terms of the deductive-nomological (DN) account. The principle is the law required by the explanans (or explaining material), the explanandum (or phenomenon to be explained) being extinction of $P$. caudatum due to $P$. aurelia.

A conception of ecological explanation formulated along the lines of Hempel's (1965) DN model faces some difficulties. ${ }^{2}$ Firstly, Weber's account of competition-based ecological expla-

\footnotetext{
${ }^{2}$ In addition to Weber (1999), Lange (2000), and Mikkelson (2003) assume, implicitly or explicitly, the DN perspective on explanations. Mikkelson examines the case when explananda are general regularities: law-like generalities that do not refer to particular biological taxa explain generalities that involve particular historical kinds (1392). By contrast, Weber and Lange focus on the case of explananda being particular facts. Most problems I will raise with respect to Weber's account of the explanatory role by direct application of the principle of competitive exclusion would also apply to the views of Lange and Mikkelson, since they adopt the same perspective on the explanatory role of laws.
}

๑ OPEN ACCESS - PTPBIO.ORG 
nation contained in the bottle-experiments of Gause does not consider important features of those experiments and how the latter explained competitive exclusion. A direct application of the principle of competitive exclusion cannot formulate a satisfactory explanation because Gause (1934) claimed that a central part of such an explanation is the "direct study of the factors limiting growth" (58). Lotka-Volterra equations express competitive exclusion and Gause thought they are needed to consider the process of competition "as a whole" (7). However, "they do not throw any real light on the underlying factors which control the growth of a population" and the acceptable way to investigate them is to study empirically the factors controlling the growth and then to express them in quantitative form (43). And Gause emphasized this idea throughout his book and applied it also to the study of competition between P. aurelia and P. caudatum. He determined experimentally that $P$. caudatum grows at a faster rate than $P$. aurelia-and so has an advantage - and quantified the growth rate for each species and the coefficients of relative food consumption. Likewise experimentally he determined that $P$. aurelia is more resistant to waste products of $P$. bursaria - the bacterium that is their food source-which confers it an advantage compared to $P$. caudatum. Given these differential advantages, which species will competitively eliminate the other one depends on "the decisive factor of competition"-rapid utilization of the food resources or resistance to waste products (Gause 1934, 112-13). Consequently, a satisfactory explanation has to consider foremost "the underlying factors which control the growth of a population" but the principle of competitive exclusion does not do this. As a result, it cannot provide a satisfactory explanation and contrary to Weber it cannot be "simply a direct application of the principle itself." Gause's insistence on the underlying factors is representative of the current mechanistic approach to competition and to other ecological phenomena, rather than of a nomothetic perspective.

Secondly, Weber's proposal does not do justice to how Gause in particular and ecologists more generally use models to describe and explain. In various sciences, including ecology, scientists use models to formulate predictions that they hope will agree with the data obtained from interaction with the world. Should the prediction agree with the data, it is concluded that the model most likely fits the world. The model would be discarded if its prediction does not agree with the data. Typically, a prediction does not exactly match data, but it closely approximates them. Of the many models that yield predictions, scientists would choose those models whose predictions better match the data and the model would be best-fitting. [ ${ }^{3}$ Gause's research implemented this epistemological conception long before philosophers have articulated it. In his words: "The quantitative expression of the growth of population must go hand in hand with a direct study of the factors which control growth. Only in those cases, where the results deduced from equations are confirmed by the data obtained through entirely different methods, by a direct study of the factors limiting growth, can we be sure of the correctness of the quantitative theories" (Gause 1934, 58). After having performed a number of experiments, Gause concludes: "the process of competition under our conditions has always resulted in one species being entirely displaced by another, in complete agreement with the predictions of the mathematical theory" (103). The mathematical theory that he refers to is the Lotka-Volterra equation of competition, which is the model used to derive the prediction that there is no equilibrium between competing species occupying the same "niche" and that one of them will be displaced (48). Considering this, it is more appropriate to conceive of the explanation of competitive exclusion not in terms of application of a law that produces an effect by causal necessity, but in terms of the fit between a model incorporating that law and experimentally obtained data, plus an empirical study of the factors limiting growth. This approach has the added benefit of not assuming that laws func-

\footnotetext{
${ }^{3}$ For a more detailed account see Ford (2000), Giere (1999), Giere, Bickle, and Mauldin (2006).
} 
tion in the complex ecological setting with deterministic force and incorporates random events, which account for the discrepancy between what is predicted and what is observed.

Thirdly, the bottle experiments that Gause and a few other ecologists performed in laboratory conditions satisfy the unrealistic assumptions of the Lotka-Volterra equations (homogeneous and constant environment, no immigration or emigration), and they did result in competitive exclusion. However, the goal of ecologists is to explain phenomena as they happen in nature, laboratory experiments being important tools toward that end. The systems that ecologists study in nature do not satisfy those assumptions. To fully explicate this type of competitionbased ecological explanation, Weber had to show how bottle-experiments and the principle of competitive exclusion are related to explanations of phenomena in natural conditions. In the absence of such a demonstration, Weber has only attempted to show how the principle could be used to explain competitive exclusion in laboratory conditions, or in limited natural situations that are isolated from disturbing influences and resemble as a result bottle experiments. Since both of these instances represent limited ranges of cases, the principle of competitive exclusion becomes a principle with a limited domain of direct application.

Fourthly, ecologists do not seem to apply in nomothetic fashion the principle to explain phenomena occurring in natural conditions even when competitive exclusion happens. For example, Amur honeysuckle (Lonicera maackii) — a shrub native to NE China-competitively excludes native flora when it grows in the USA. Ecologists studying it talk about its competitive edge or ability that is due to various life-history traits in the context of habitat structure, dynamics of ecological communities, and ecosystem processes and function (McNeish and McEwan 2016). They could have formulated an explanation by applying directly the principle of competitive exclusion. That they did not do that, but prefer the meticulous documentation of how lifehistory traits allow this species to exclude native flora indicates that ecologists have a standard of explanation that is mechanistic, not nomological. Thus, Weber has yet to offer a convincing illustration of how the principle of competitive exclusion explains by direct application to a phenomenon in the wild.

To address these difficulties, I propose rethinking explanation by direct application of competitive exclusion principle as well as of other ecological laws in terms of the covering-law model explanation that I examine next.

\subsection{An Alternative Proposal: Covering-Law Model Explanations}

Elgin and Sober (2002) offer a view on the explanatory role of laws that Bokulich (2011) calls covering-law model explanation. Elgin and Sober argue that the explanans explains the explanandum "not by entailing it or by conferring a probability on it (high or low), but by showing that the value described in the explanandum is close to the value predicted by the idealization" (448). The explanans must contain (a) descriptions of the initial conditions, and (b) an idealized model. They use optimality models to illustrate their proposal:

(i) Idealized law entailed by the optimality model: "If organisms are fitter the closer they are to the optimal value $\alpha$ and if no forces other than selection are at work in the population, then the population will evolve to a state in which all organisms exhibit the trait value $\alpha . "$

(ii) Partial description of initial conditions: "Organisms are fitter the closer they are to the optimal value $\alpha$."

(iii) Observed facts: "The $n$ organisms in the population have trait values $\beta_{1}, \beta_{2}, \ldots$, $\beta_{n}$ (where each $\beta_{i}$ differs only negligibly from $\alpha$ ).” (Elgin and Sober 2002, 447) 
Propositions (i) and (ii) explain (iii) in the sense that they show that the value described in (iii) is close to that predicted by (i) and (ii). Propositions (i) and (ii) do not make up a complete explanation, since they do not describe all causally relevant factors; nonetheless, they are explanatory (Elgin and Sober 2002, 447). The model plays a central role in this account, and its explanatory role is grounded in its ability to represent the pattern of counterfactual dependence specific to the target system.

A good example to illustrate the application of the covering-law model for reconstructing explanations using the principle of competitive exclusion can be extracted from Tilman's (1977) research on resource competition that he later developed into a theory of resource competition and community structure (Tilman 1982). Gause's work is less suitable for such an illustration because he did not make specific predictions about the outcome of competition between the microorganisms he used. Tilman, however, did a "direct study of the factors limiting growth" which are the physiological constants of phosphate and silica requirements by two species of freshwater algae (Asterionella formosa and Cyclotella meneghiniana), and predicted under what conditions they will coexist or one of them will dominate. Predictions were then compared with observed data. His experiments used media with varying concentrations of the limited resources phosphate and silica, cultures of the two species of algae, and two different models of resource competition-Monod equations and the variable internal stores model of growth-which he used separately to determine how well "single species physiological information can predict the outcome of competition" $(1977,338)$. Importantly for this discussion of the explanatory role of the competitive exclusion principle, Tilman (1977) notes that both models are analogous to the Lotka-Volterra equations (347). One experiment began with cultures containing $\approx 1,000$ cell $/ \mathrm{mL}$ of each species, the medium being phosphate limited. 24 days later, there were no cells of Cyclotella in the $1 \mathrm{~mL}$ sample counted, whereas the count of Asterionella was $>10^{4}$, indicating competitive exclusion of the former species. Competitive dominance was defined as the situation when a species comprised $95 \%$ or more of the cells from the culture. What explains this competitive success of Asterionella? A covering-law model explanation would look as follows:

(i) Idealized law: Monod model of growth of a single species limited by a single resource; it states that of all the nutrients that are potentially limiting, the one nutrient that is most limiting will completely determine the growth rate of a species;

(ii) Partial description of initial conditions: (a) experimentally determined physiological constants of levels of phosphate and silicate concentrations required for the growth of Asterionella and Cyclotella; (b) varying concentrations of phosphate and silica in the medium and varying flow rates;

(iii) Graphical model predicting in light of (i) and (ii) that Asterionella should be dominant in regions with limited phosphate, Cyclotella will dominate in silicate limited regions, and species coexistence in regions in which both species are limited by different resources.

(iv) Observed facts: no cells of Cyclotella and $>10^{4}$ cells of Asterionella in a phosphate limited medium.

Results predicted in (iii) show close fit to observed data (iv). Monod model and description of the initial conditions explain observed data by showing that the derived competitive dominance of Asterionella is close to the actual data, and how the observed data could have changed if the physiological constants of phosphate and silica requirements, proportion of these limited resources in the environment had been different. Equations of the Monod model represent 
ecological processes "as a whole," Gause could have said. Moreover, Tilman's account of competitive dominance and coexistence of the two species of algae also explains over $70 \%$ of observed variance of the two species along a natural gradient of phosphate and silica in Lake Michigan $(1977,348)$. This implies that the covering-law model applies both to phenomena constructed in the lab and to those in the wild. In both cases predictions derived from the model and descriptions of initial conditions are compared for fit with observed data.

The covering-law model similarly accounts for the explanatory role of Malthus's law when applied to cases that show exponential growth, even if Ginzburg and Colyvan do not ascribe it this explanatory role. Such growth happens for instance in invasive species, or in cases without predation and interspecific competition. ${ }^{4}$ For examples, see Rockwood (2015) and Gotelli (2008). Additionally, possibly all of the proposed ecological laws listed in section 1 could be used as an idealized law in a covering-law model explanation. Since most proposals of those laws are also principles from population ecology, which relies heavily on model building and testing of predictions of models against actual data, this proposal has the added benefit to better account for explanations from population ecology than the DN perspective.

Furthermore, the covering-law model view on explanation and its illustrations help respond to objections raised in section 2.1 to constructing ecological explanation in terms of the DN model. I answer them in a different order, though: (2) Because the covering-law model account uses models to formulate predictions and test them against observed data when formulating explanations, it is consistent with this practice of ecologists. Additionally, it also deals with discrepancies between observed numbers and those derived from the model plus descriptions of initial conditions, since models are accepted based on how closely their predictions match observed data. (3) The covering-law model applies to explanations of ecological phenomena in the wild and in the lab, as shown by Tilman's extension of lab results to the natural conditions of lake Michigan.

Responding to objection (1) based on Gause's work, it has to be observed that it is not the case that the covering-law model does not accept an explanatory role for mechanisms as the notion "law" from its name might suggest. Tilman developed and argued for a mechanistic theory of competition, the notion "mechanism" referring to physiological, morphological, or behavioral features of a species. The different requirements for silica and phosphate that Asterionella and Cyclotella exhibit are physiological features that make up a mechanism in Tilman's sense and they are listed next to the varying concentrations of phosphate and silica under condition (ii). Identification of the physiological, morphological, or behavioral features represents the "direct study of the factors limiting growth" that Gause required ecological explanations to be based on. Descriptions of initial conditions can thus accommodate descriptions of mechanisms as well as other "factors limiting growth." In addition, models from condition (i) represent various eco-

\footnotetext{
${ }^{4}$ To illustrate application of the covering-law model to exponential growth, I use an example of exponential growth in the wild based on Gotelli (2008), but with slight modifications. In 1937, eight pheasants were introduced onto Protection island, close to the coast of Washington State, that had abundant food resources and lacked predators. Distance between the island and the coast precluded migration. By 1938 the population increased to 30 birds, and to 418 by 1940 . Why did the population of pheasants number 418 individuals in 1940 ? A covering-law model explanation proceeds as follows:

(i) Idealized law: Law of Exponential Growth/Malthus's Law: $N_{t}=N_{0} e^{r t}$.

(ii) Partial description of initial conditions: there were 8 birds in 1937.

(iii) Partial description of initial conditions: the rate of increase $r$ was $\ln (3.75)=1.3217$.

(iv) Observed facts: there were 418 birds by 1940.

From (i), (ii), and (iii), which make up the explanans, one deduces the population size to be 421 in 1940 , yet the actual size was 418 . The model expressing the law and the initial conditions explain the observed data by showing that the derived population size 421 is close to the actual data, and how the observed data could have changed if the rate of increase or the initial population size had been different.
} 
logical processes "as a whole," satisfying another expectation of Gause. Finally, that ecologists studying invasive species concentrate on discovering mechanisms of competitive success indicates the inability of the general principle of competitive exclusion to explain without a detailed description of the particular mechanism and its limited domain of application, but this is not a shortcoming of the covering-law model of explanation, which cannot have as a reconstruction of ecological explanation more than what ecologists themselves are putting in it. Even with a limited domain of application of ecological laws, the covering-law model of explanation fares better than the DN model, as I have shown so far.

The foregoing analysis has demonstrated that mechanisms are important in ecological explanations even when they appeal to laws of ecology. Yet mechanisms play a more prominent role. The principle of competitive exclusion, or Malthus's law apply to different ecological phenomena and are invariant across them. What explains the particular different phenomena is not the competitive exclusion principle, or Malthus's law, but the mechanisms characteristic to specific cases. Competition between Asterionella and Cyclotella, P. aurelia and P. caudatum, L. maackii and native plants involve the principle of competitive exclusion, but the mechanisms are different. In one case it is physiological requirements of silica and phosphate, in the other it is resistance to waste of Bacillus pyocyaneus, and in the latter it is a cohort of mechanisms: early leafing and late senescence, production of allelochemicals by roots and shoots, above-ground competition for light and below-ground competition for water and nutrients, lack of predators, etc. Consequently, even the explanatory use of laws in ecology make a case for the explanatory importance of mechanisms.

Responding to a concern from an anonymous reviewer should contribute to clarifying the relationship between mechanisms and laws. According to that concern, "since 'mechanisms' themselves involve appeal to laws, ecological explanations that make use of mechanisms are in fact still making use of laws." To respond to this objection, it is important to clarify what ecological mechanisms are and how they are different from laws. I have tentatively characterized individual-level ecological mechanisms for a phenomenon as consisting of "entities, biotic or abiotic, that perform specific activities and are organized in certain ways by virtue of their properties such that they are responsible for the phenomenon" (Pâslaru 2017, 359). To the extent that laws govern these components of mechanisms they are not ecological laws, but laws of physics, chemistry, physiology, or other sciences that study phenomena that are more fundamental than phenomena of ecology in the conventional ontological hierarchy. When ecologists describe and then model mechanisms, they do not refer to the laws of these more basic sciences or to other laws of ecology, but describe properties of entities, their behaviors and organization, just like Tilman did when he described the silica and phosphate requirements of algae.

\section{Ecological Laws as Descriptors of Default States}

Discussions of laws of ecology rely on an analogy with Newton's first law: In the absence of forces acting on an object, the acceleration of the object is zero (Serway and Jewett 2008). This analogy serves two purposes: (1) to argue that ecology has laws (Colyvan and Ginzburg 2003), and (2) to describe the role of these laws in explanations (Weber 1999, Colyvan and Ginzburg 2004). Following this analogy, Colyvan and Ginzburg, and Weber identify different laws of ecology, yet they see them as playing the same role of descriptors of a default state that one would expect to occur. Usually the observed state deviates from the expected default and descriptions of mechanisms are necessary to account for the deviation from the default. The logic of ecological explanation becomes similar to explanations in classical mechanics that use Newton's first law. In this role, laws are part of explanations of instances to which they "do not actually apply" (Weber

๑ OPEN ACCESS - PTPBIO.ORG 
1999, 83). This is the second role that laws of ecology play in explanations, and I examine it next.

\subsection{Ginzburg and Colyvan: Laws as Descriptors of Default States Acted Upon by Mechanisms}

Ginzburg was the first to argue that Malthus's law is analogous to Newton's first law and that it is the only formula in population dynamics that deserves the term "law," all the other formulas being models (Ginzburg 1986). With Colyvan, he proposed a research program for ecology modeled after Newtonian principles (Colyvan and Ginzburg 2003a, 2003b, Colyvan and Ginzburg 2010, Ginzburg and Colyvan 2004). They argue that similarly to Newton's first law, Malthus's law describes a default state of a growing population when no disturbing forces are present. Analogously to the second law of classical physics that defines the concept of force as a quantity resulting in acceleration, Ginzburg and Colyvan (2004) 'define 'ecological forces' quantities that act on growing (or declining) populations as second-order quantities-'ecological accelerations' "(101). Similarly to physics, Malthus's law and the definition of ecological forces open up a research program to identify ecological forces, or mechanisms-a term that they also use- that affect the dynamics of populations.

Maternal effect is one of the mechanisms influencing the growth of a population. It causes inertia in population dynamics due to daughters' reproduction responding both to their conditions as well as to conditions experienced by their mothers. When mothers experience plentiful resources, this leads to births overshooting the equilibrium value of the population, and to undershooting that value when they are undernourished. As a result, the population can oscillate around the equilibrium value (Ginzburg and Colyvan 2004, 50). When this maternal effect is incorporated into the exponential growth equation, it yields this model that assumes nonoverlapping generations:

$$
\begin{aligned}
& N_{t+1}=R N_{t} f\left(X_{t}\right) \\
& X_{t+1}=X_{t} g\left(\frac{S}{N_{t+1}}\right)
\end{aligned}
$$

$N$ is population abundance, $X$ is the average individual quality, while parameter $R$ is the maximum population growth rate of individuals of very high average quality. $R$ is assumed to be greater than 1 . If $R<1$, the population will decline; $t$ represents time in generations; $f$ is a monotonically increasing function of quality, $X$, while $g$ is a monotonically increasing function of per capita food, $S / N_{t+1}$ (Ginzburg and Colyvan 2004, 50-51).

The covering-law model accounts for the explanatory use of Malthus's Law in conjunction with the maternal effect mechanism, given Ginzburg and Taneyhill's (1994) assessment of this model in contrast to delayed logistic models by fitting it to empirical data on the periods of oscillations of six populations of different forest moth species. The better fit of the maternal effect model is a key premise in their reasoning that concludes: "the maternal effect model must be considered as a strong contender for explaining cycles in forest moths" (88). A covering-law model reconstruction of their explanation would look thus:

(i) Idealized model: model (11) incorporating the Malthus's law and the maternal effect mechanism;

(ii) Partial description of initial conditions: changing availability of resources for mothers at times $t_{n}$ and $t_{n+1}$, average individual quality, population growth rate;

(iii) Cycles periods of six species predicted in light of (i) and (ii).

๑ OPEN ACCESS - PTPBIO.ORG 
(iv) Observed facts: observed cycle periods of six species.

On this account, model (11) and description of initial conditions (ii) explain observed data (iv) by showing that predictions (iii) it produces closely match observed data. Note that a model of mechanism is part of the idealized model that does the explaining, but it could be formulated separately from the law. The law of exponential growth and the description of initial conditions cannot explain the change in population abundance without a description of the mechanism driving that change in population abundance. Furthermore, multiple ecological forces, or mechanisms could be acting on a growing population, preventing the default state from occurring. The problem for ecologists is to identify those mechanisms and determine their significance in slowing the population growth. The default state is one, yet the mechanisms are multiple, and so the explanatory burden falls on identifying the mechanisms without which the Malthus's law is explanatorily powerless, and "only empirical work can tell us what the true mechanisms are. We have no illusions about this being an easy task," conclude Ginzburg and Taneyhill (1994, 88).

\subsection{Weber: Laws as Descriptors of a Default State as a Contrast Class}

Hutchinson's (1961) work on plankton underlies Weber's (1999) proposal[ that the principle of competitive exclusion describes a default state that one would expect to occur, but it does not, yet "we can trust it in the work of finding out what has happened to cause its empirical falsification" (Hutchinson 1961, 143). On this proposal, the structure of explanations in community ecology of coexisting organisms with similar ecological requirements contains these elements: (i) a description of coexisting species requiring similar limited resources, (ii) a description of the contrast class (only the species that is the superior competitor exists) based on the principle of competitive exclusion, and (iii) a causal mechanism - such as environmental variation-which shows how the coexisting species evade competitive exclusion. Coexistence described in (i) is in need of explanation, which is sought against the background of competition theory associated with the principle of competitive exclusion (Weber 1999, 82-83).

Weber makes a compelling case for the contrastive role of the principle of competitive exclusion in explanations from community ecology and I see no major reasons to dispute it, but I will make a few observations about some aspects that require future work. Yet I am not dismissing the concerns raised lately about this principle. It is viewed as circular and able to predict coexistence of species occupying the same niche, rather than competitive exclusion, and competitive exclusion of those that are dissimilar, rather than their coexistence (Keddy 2000; Johnson and Bronstein 2019), and it does not work as a contrast class for small populations (Melbourne and Hastings 2008). These objections question its ability to describe a default state, as well as its heuristic value to help make questions more precise. The limits of this article do not allow me to address in detail all these issues.

In his attempt to articulate the aim and structure of ecological theory of interspecific competition, Weber (1999) focuses on the law-like character of the principle of competitive exclusion and its role of descriptor of a contrast class, but he sheds less light on the nature of mechanisms. It is clear that they are a necessary step in explaining coexistence: "The explanation then proceeds by citing a causal mechanism - environmental variation-which shows how the algae can evade competitive exclusion" (83). Besides environmental variation, hidden niche differences, predation, or a combination of such mechanisms might be responsible for coexistence of

\footnotetext{
${ }^{5}$ Raerinne and Baedke (2015) adopt this view as all, yet they do not show on the basis of an ecological example how exactly appeal to the competitive exclusion principle helps answer the research question, but make a general case for it. Hence, objections raised to Weber's view apply to their reasoning as well.
}

๑ OPEN ACCESS - PTPBIO.ORG 
species (Weber 1999, 82). However, mechanisms play a more prominent role in the structure of ecological theory and explanatory practice than Weber's brief account discloses.

Ecologists, both past and present, take competitive exclusion as a background assumption, yet appear to concentrate on identifying the mechanisms responsible for preventing exclusion and on determining their combination and significance in making coexistence of species a reality. The same principle of competitive exclusion is assumed in a great variety of cases, but the mechanisms explaining departure from exclusion are many and different, which further indicates the explanatory weight of mechanisms. The task of identifying them is far from trivial, since "myriad mechanisms can promote coexistence through species differences" (Leibold and McPeek 2006, 1403; see also Chesson 2000). That this task requires joining the efforts of two opposing perspectives - the niche differentiation perspective and the neutral community view, the latter being important for drawing attention to other processes and dynamics of groups of species (Leibold and McPeek 2006) — further underscores its significance. Hutchinson himself devotes the bulk of his 1961 plankton article on articulating possible mechanisms and processes that could explain coexistence of the many species of phytoplankton. This insistence of ecologists on the identification of mechanisms indicates that an articulation of the structure of the theory of interspecific competition has to incorporate a typology of ecological mechanisms, an account of how they are related, and a description of experimental strategies for identifying the constituents of mechanisms and for ensuring that their descriptions are empirically adequate. This is a task for future philosophical work.

A further difficulty that Weber's perspective has to address is that competitive exclusion is not always a contrast class even in cases that show such exclusion. For example, research on invasive species takes the default state, and thus the contrast class, to be coexistence rather than competitive exclusion. Ecologists studying the introduced shrub Amur honeysuckle (Lonicera maackii), and similar invasive species, ask "Why does this plant successfully displace native species in the introduced range rather than coexist with them as it does in its native habitat or in European habitats?" (Luken and Thiered 1996; Callaway and Ridenour 2004). The contrast class in such cases is not competitive exclusion, but coexistence.

\section{Conclusion}

That laws of ecology play a central role in explanations by direct application or by describing a contrast class does not minimize the role of mechanism descriptions. On the contrary, their role becomes more prominent. When ecological laws are applied as part of a covering-law model to explain phenomena, descriptions of mechanisms are still necessary to explain the difference between observed data and those predicted from the model. When laws are used as descriptors of default states or contrast classes, the explanatory burden falls on the identification of mechanisms that cause deviation of observed phenomena from the condition described by the contrast class. In many instances of explanations in ecology laws are not even mentioned, explanations being articulated entirely in terms of mechanisms. Given this centrality of mechanisms in ecology, further philosophical work on explanations in ecology has to produce a typology of ecological mechanisms, an account of how they are related, and a description of strategies for experimentally identifying the constituents of mechanisms and for ensuring that their descriptions are empirically adequate. 


\section{Acknowledgments}

I am grateful to two anonymous reviewers and to Massimo Pigliucci for their comments on an earlier version of the manuscript that helped produce the improved final version. Many thanks go to Marylin Marx and Christopher Eliot for correcting mistakes of English. All remaining errors are mine.

\section{Literature cited}

Berryman, A. A. 1999. Principles of Population Dynamics and Their Application. Cheltenham: Stanley Thornes.

Berryman, A. A. 2003. "On Principles, Laws, and Theory in Population Ecology." Oikos 103 (3): 695701. doi: https://doi.org/10.1034/j.1600-0706.2003.12810.x.

Bokulich, Alisa. 2011. "How Scientific Models Can Explain.” Synthese 180 (1): 33-45. doi: https: //doi.org/10.1007/s11229-009-9565-1.

Callaway, Ragan M. and Wendy M. Ridenour. 2004. "Novel Weapons: Invasive Success and the Evolution of Increased Competitive Ability." Frontiers in Ecology and the Environment 2: 436-443. doi: https://doi.org/10.1890/1540-9295(2004)002\{[\}0436:NWISAT\{]\}2.0.CO;2.

Chesson, Peter. 2000. "Mechanisms of Maintenance of Species Diversity." Annual Review of Ecology and Systematics 31: 343-366. doi: 10.1146/annurev.ecolsys.31.1.343.

Colyvan, Mark, and Lev R. Ginzburg. 2010. "Analogical Thinking in Ecology: Looking beyond Disciplinary Boundaries.” The Quarterly Review of Biology 85 (2): 171-182. doi: 10.1086/652321.

Colyvan, Mark, and Lev R. Ginzburg. 2003a. “The Galilean Turn in Population Ecology.” Biology and Philosophy 18: 401-414. doi: https://doi.org/10.1023/A:1024121002194.

Colyvan, Mark, and Lev R. Ginzburg. 2003b. "Laws of Nature and Laws of Ecology." Oikos 101 (3): 649-653. doi: 10.1034/j.1600-0706.2003.12349.x.

Cooper, Gregory John. 2003. The Science of the Struggle for Existence: On the Foundations of Ecology. Cambridge and New York: Cambridge University Press.

Elgin, Mehmet, and Elliott Sober. 2002. "Cartwright on Explanation and Idealization." Erkenntnis 57: 441-450. doi: https://doi.org/10.1007/978-94-017-1009-1_9.

Ford, E. David. 2000. Scientific Method for Ecological Research. Cambridge: Cambridge University Press.

Gause, G. F. 1934. The Struggle for Existence. Baltimore: The Williams \& Wilkins Company.

Giere, Ronald N. 1999. Science Without Laws. Chicago: University of Chicago Press.

Giere, Ronald N., John Bickle, and Robert F. Mauldin. 2006. Understanding Scientific Reasoning. 5th edition. Belmont: Thomson Higher Education.

Ginzburg, Lev R. 1986. “The Theory of Population Dynamics: I. Back to First Principles.” Journal of Theoretical Biology 122 (4): 385-399. doi: 10.1016/S0022-5193(86)80180-1.

Ginzburg, Lev R., and Mark Colyvan. 2004. Ecological Orbits: How Planets Move and Populations Grow. New York: Oxford University Press.

Ginzburg, Lev R., and Dale E. Taneyhill. 1994. "Population Cycles of Forest Lepidoptera: A Maternal Effect Hypothesis.” Journal of Animal Ecology 63 (1): 79-92. doi: 10.2307/5585.

Gotelli, Nicholas J. 2008. A Primer of Ecology. 4th edition. Sunderland: Sinauer Associates, Inc.

Hempel, Carl Gustav. 1965. Aspects of Scientific Explanation and Other Essays in the Philosophy of Science. New York: Free Press. 
Hutchinson, George E. 1957. "Concluding Remarks.” Cold Spring Harbor Symposia on Quantitative Biology 22: 415-427.

Hutchinson, George E. 1961. “The Paradox of the Plankton.” American Naturalist 93 (882): 145-159. doi: $10.1086 / 282171$.

Johnson, Cristopher A. and Judith L. Bronstein. 2019. "Coexistence and Competitive Exclusion in Mutualism.” Ecology 100 (6): e02708. doi: 10.1002/ecy.2708.

Lange, Marc. 2000. Natural Laws in Scientific Practice. Oxford and New York: Oxford University Press.

Lange, Marc. 2005. "Ecological Laws: What Would They Be and Why Would They Matter?” Oikos 110 (2): 394-403. doi: 10.1111/j.0030-1299.2005.14110.x.

Leibold, Matthew A. and Mark A. McPeek. 2006. "Coexistence of the Niche and Neutral Perspectives in Community Ecology.” Ecology 87 (6): 1399-1410. doi: 10.1890/00129658(2006)87[1399:CO'TNAN]2.0.CO;2.

Linquist, Stefan, T. Ryan Gregory, Tyler A. Elliott, Brent Saylor, Stefan C. Kremer, and Karl Cottenie. 2016. "Yes! There are Resilient Generalizations (or 'Laws') in Ecology." The Quarterly Review of Biology 91 (2): 119-131. doi: 10.1086/686809.

Lockwood, Dale R. 2008. "When Logic Fails Ecology.” The Quarterly Review of Biology 83 (1): 57-64. doi: https://doi.org/10.1086/529563.

Luken, James O. and John W. Thieret. 1996. “Amur Honeysuckle, Its Fall From Grace.” BioScience 46 (1): 18-24. doi: 10.2307/1312651.

McNeish, Rachel E., and Ryan W. McEwan. 2016. "A Review on the Invasion Ecology of Amur honeysuckle (Lonicera maackii, Caprifoliaceae) A Case Study of Ecological Impacts at Multiple Scales." The Journal of the Torrey Botanical Society 143 (4): 367-385. doi: 10.3159/TORREY-D15-00049.1.

Mikkelson, Gregory M. 2003. "Ecological Kinds and Ecological Laws.” Philosophy of Science 70 (5): 1390-1400. doi: 10.1086/377416.

O’Hara R. B. 2005. “The Anarchist's Guide to Ecological Theory. Or, We Don't Need No Stinkin' Laws." Oikos 110 (2): 390-393. doi: 10.1111/j.0030-1299.2005.13959.x.

Pâslaru, Viorel. 2017. "Mechanisms in Ecology." In The Routledge Handbook of Mechanisms and Mechanical Philosophy, edited by Stuart Glennan and Phyllis Illari, 348-361. London and New York: Routledge.

Raerinne, Jani, and Jan Baedke. 2015. "Exclusions, Explanations, and Exceptions: On the Causal and Lawlike Status of the Competitive Exclusion Principle." Philosophy \& Theory in Biology 7 (2): e602. doi: dx.doi.org/10.3998/ptb.6959004.0007.002.

Rockwood, Larry L. 2015. Introduction to Population Ecology. 2nd edition. West Sussex: John Wiley \& Sons.

Serway, Raymond A., and John W. Jewett. 2008. Physics for Scientists and Engineers. Belmont: Thomson Publishing Company.

Tilman, David. 1977. "Resource Competition between Plankton Algae: An Experimental and Theoretical Approach.” Ecology 58 (2): 338-348. doi: 10.2307/1935608.

Tilman, David. 1982. Resource Competition and Community Structure. New Jersey: Princeton University Press.

Turchin, Peter. 2001. “Does Population Ecology Have General Laws?” Oikos 94 (1): 17-26. doi: 10.1034/j.1600-0706.2001.11310.x. 
Weber, Marcel. 1999. “The Aim and Structure of Ecological Theory.” Pbilosophy of Science 66 (1): 7193. doi: $10.1086 / 392677$.

West, Geoffrey B., and James H. Brown. 2004. “Life's Universal Scaling Laws.” Physics Today 57 (9): 36-43. doi: 10.1063/1.1809090.

(C) 2022 Author(s)

This is an open-access article distributed under the terms of the Creative Commons Attribution 4.0 International license, which permits anyone to download, copy, distribute, display, or adapt the text without asking for permission, provided that the creator(s) are given full credit.

ISSN 2475-3025 